\title{
ESTÁGIO DE DOCÊNCIA ORIENTADA NA ESCOLA ESTADUAL DE ENSINO MÉDIO PROFESSORA MARIA ROCHA, SANTA MARIA/RS
}

http://dx.doi.org/10.5902/2318133829648

\author{
Janaína de Arruda Carilo Schmitt \\ Lubia Telma Garcia Wustrow Souza \\ Colégio Técnico Industrial da UFSM, Brasil.
}

\begin{abstract}
Resumo
Por meio deste texto apresenta-se o relato das atividades desenvolvidas no estágio de docência vinculado ao Programa de Formação de Professores para Educação Profissional e Tecnológica PEG/UFSM -, o qual foi realizado na Escola Estadual de Ensino Médio Professora Maria Rocha, nos cursos técnicos de Contabilidade e Secretariado, nas disciplinas de Organização e Técnicas Comerciais e Psicologia. O estágio de docência foi o primeiro exercício da prática profissional em que houve momentos de ansiedade na preparação das aulas, estudo sobre os conteúdos que deveriam ser trabalhados com os alunos e a constante preocupação em propor metodologias inovadoras no processo de ensino. Destacam-se reflexões acerca da prática docente, em especial relacionadas com os pontos positivos e negativos, dificuldades, desafios e contribuições da experiência de inserção profissional.
\end{abstract}

Palavra-chave: estágio de docência; formação de professores; metodologias de ensino.

\section{TEACHING STAGE ORIENTED IN THE STATE SCHOOL OF MIDDLE SCHOOL TEACHER MARIA ROCHA, SANTA MARIA/RS}

\begin{abstract}
This paper presents the report of the activities developed in the teaching stage linked to the Teacher Education Program for Professional and Technological Education (PEG / UFSM), which was held at the State High School Professor Maria Rocha, in the courses Technical of Accounting and Secretariat, in the disciplines of Organization and Commercial Techniques and Psychology. The teaching stage was the first exercise of professional practice in which there were moments of anxiety in the preparation of classes, a study about the contents that should be worked with the students and the constant concern to propose innovative methodologies in the teaching process. We highlight reflections about teaching practice, especially related to the positive and negative points, difficulties, challenges and contributions of the experience of professional insertion.

Key-word: teaching stage; teacher training; teaching methodologies.
\end{abstract}




\section{Introdução}

$\mathrm{O}$ estágio docente é uma etapa fundamental para que os futuros profissionais educadores amparados pelas fundamentações teóricas coloquem em prática seus conhecimentos. Nesta oportunidade os professores em formação são apresentados às realidades de cada escola, aos projetos político-pedagógicos, alunos, professores experientes. Para Freire (1996) é na formação do professor que devemos exercitar a reflexão crítica sobre a prática que iremos desenvolver no estágio. Nesta perspectiva a autonomia e a criação são testadas e o docente tem a possibilidade de construir conhecimentos e compartilhar saberes.

Pelo estágio desenvolvem-se experiências em atividades de ensino. Tais atividades são desenvolvidas sob a responsabilidade de um professor orientador que supervisiona a prática auxiliando o aprendiz em seus anseios diários. A necessidade do cumprimento desta etapa na formação se faz presente tanto nas licenciaturas quanto nos cursos de mestrado, doutorado e de formação de professores reverenciando a prática pedagógica em conjunto aos ensinamentos teóricos, buscando novos paradigmas para compreendêlo epistemologicamente.

O docente passa a ser objeto constituinte de saberes individuais, profissionais e vivenciais que ao longo da vida vai acumulando conhecimentos e experiências que serão fundamentais na sua formação. A docência é uma atividade desafiadora que exige dos professores uma educação continuada, disposição para mudanças, inovações tecnológicas e metodológicas. O professor deve saber lidar com a complexidade da profissão. Imbernón (1994), afirma que a formação de professores precisa ajudá-lo a enfrentar os desafios que irá encontrar no seu campo de trabalho frente às frequentes mudanças da realidade.

Freire (1996), em A pedagogia da autonomia, faz uma abordagem reflexiva sobre a formação de professores e destaca que o educando deve estar aberto a indagações, às perguntas e curiosidades dos alunos criando junto com eles a produção de conhecimentos através de um ensino que vá além da simples transmissão ou transferência dos conhecimentos. Dessa forma, o autor defende que o rigor do pensar certo para fazer certo nega uma prática de preconceito, e que educadores e educadoras devem despertar o senso crítico e pensante de seus alunos, transformando os mesmos em seres sociais capazes de se desenvolverem e se posicionarem culturalmente.

É preciso compreender a teoria para refletir sobre a prática e essa é a função do estágio docente. Para Saviani (1992), a competência técnica engloba o domínio teórico e prático dos princípios e conhecimentos que regem uma instituição escolar, assim, mesmo um professor em formação sem experiência docente é capaz de obter uma formação sólida se estiver amparado pela teoria, pela prática e pela reflexão.

Ensinar a aprender construindo saberes e mediando novos conhecimentos é um processo constante para uma educação resiliente e expansiva. $O$ uso da tecnologia e de metodologias de ensino são ferramentas cada vez mais importantes para os educadores e educadoras. A metodologia constitui a doutrina do método, discute, organiza e orienta os estudos, investiga os pressupostos teóricos e é responsável pela aplicação dos princípios gerais de uma ciência. 
Para Freire (1997) o método parte do estudo da realidade e da organização dos dados, surgindo temas geradores extraídos de problematizações da prática de vida dos educandos. Os conteúdos de ensino são resultados de uma metodologia dialógica. Assim, as metodologias de ensino são aprendizagens significativas trabalhando com o dia-a-dia dos indivíduos, com suas vivências. De maneira simplista, as metodologias de ensino são estudos das diferentes trajetórias traçadas e planejadas pelos educadores aliadas às experiências de cada educando com vistas a um ensino mais abrangente onde o professore passa de detentor de todo poder e conhecimento a um agente mediador que auxilia na produção e construção de saberes.

Neste contexto, o estágio docente busca a integração da prática propondo novas ideias para o processo de ensino. O artigo 17 do Regulamento do programa de demanda social da Capes, aprovado pela portaria n. 52, de 26 de setembro de 2002, define o estágio de docência como "parte integrante da formação do pós-graduando, objetivando a preparação para a docência e a qualificação do ensino". Assim, o estágio pode ser considerado como uma "atividade teórica que permite conhecer e se aproximar da realidade" (Pimenta \& Lima, 2004, p. 13). Não podemos considerá-lo apenas como uma instrumentalização técnica, pois seu objetivo deve ir além de ensinar conteúdos e modos de fazer a serem aplicados nas situações reais.

\section{Reflexões sobre a prática docente Pontos positivos}

Os pontos positivos foram diversos: vivência de sala de aula, prática da docência, superação, desinibição, troca de conhecimentos, construção de conhecimentos e experiências. Foram momentos que proporcionaram a oportunidade de aproximar o aprendiz professor da realidade concreta e o desenvolvimento de habilidades como: autonomia intelectual, domínio dos conteúdos e metodologias, visão ética e política da prática profissional. O estágio supervisionado aproxima os indivíduos envolvidos no convívio às diversas situações da escola que servirão como experiência de aprendizagem profissional.

\section{Pontos negativos}

Os pontos negativos sentidos durante a realização do estágio foram poucos e pontuais, tais como, as constantes alterações administrativas e funcionais da escola, por exemplo, cancelamento de aulas sem aviso prévio, mudanças semanais dos horários, insuficiência de ferramentas tecnológicas. No contexto de sala de aula constatou-se a dificuldade dos alunos em compreender normas técnicas e de concentração até o final de cada período.

\section{Dificuldades}

Durante a realização do estágio algumas dificuldades foram surgindo, tais como: comunicação extraclasse com os alunos, pois, não são todos que tem acesso à internet; a compreensão e interpretação dos textos complementares sugeridos aos alunos, assim como reunir os materiais de ensino que cumpram com todos os requisitos apresentados no componente curricular. Diante de tais dificuldades algumas estratégias foram tomadas: àqueles alunos que não tinham acesso à internet, os materiais foram impressos e 
entregue em aula; as atividades complementares foram diversas vezes explicadas e oralizadas em sala de aula e os materiais didáticos foram adaptados às necessidades das disciplinas, vídeos complementares também auxiliaram como metodologias de ensino.

\section{Desafios}

Os desafios enfrentados na trajetória inicial no campo docente foram: estimular a motivação de cada aluno e, num universo de escola, conciliar as vivências distintas de cada discente. Sendo assim, fomos cotidianamente contextualizando tais experiências às aulas e conteúdos abordados, desviando em muitas ocasiões o foco para melhor perceber cada aluno. Outro desafio encontrado na disciplina de Organização e Técnicas Comercial foi a incessante busca para unir a turma, pois, havia uma aluna que apresentava alguns sinais de desequilíbrio emocional. Desse modo, buscar a compreensão e empatia de todos foi difícil, já que o foco principal das aulas era o aprendizado e a interação entre todos do grupo.

Diante deste cenário de escola e sala de aula um dos questionamentos que sempre estava presente em nossos pensamentos era como otimizar o curto tempo dos períodos ou encontros com os alunos dentro do ambiente das salas de aula? Desse modo sempre estávamos atentas das responsabilidades com os conteúdos obrigatórios, na transferência ou mediação dos conhecimentos aos nossos alunos com máxima qualidade possível, sem deixar de lado as necessidades da turma e seus problemas mais pontuais, sendo que esses poderiam comprometer o andamento positivo de aprendizagem de cada aluno.

Um terceiro desafio foi a preparação para as aulas, pois apesar da formação em acadêmica ser bastante abrangente e interdisciplinar, a linguagem técnica utilizada poderia não ser compreendida pela turma inicialmente. Sendo assim, foram necessários ajustes no vocabulário e fontes de pesquisa, para que, então, começasse a fazer parte dos contextos vividos pelos alunos e assim facilitar seu entendimento. Nesse momento percebemos o quão presente é o esquecimento dos professores mais experientes na empatia para melhor compreender seus alunos.

Ainda é relevante mencionar nossas incertezas ao lidar com a evasão escolar, seja por desistência, seja por trancamento, uma vez que nós docentes iniciamos as atividades com turmas completas, mínimo de 20 alunos, e findamos com uma média de 10 a $20 \%$ de alunos evadidos. Percebe-se que esta situação causa preocupação por parte dos coordenadores e dos próprios discentes frequentes, devido ao interesse mútuo em resgatar os desistentes para que não percam a oportunidade de uma qualificação profissional pública e gratuita.

\section{Contribuições}

As contribuições do estágio supervisionado para formação profissional são inegáveis. Por meio dele foi possibilitado o contato direto com a escola e seus componentes curriculares. Assim, além de ser uma exigência da Lei de Diretrizes e Bases da Educação, esta experiência é necessária para a educação profissional, pois, integra o professor aprendiz ao ambiente escolar e possibilita a concretização da prática profissional, sendo uma oportunidade de crescimento profissional. 
O ensino pragmático dos programas de iniciação docente são princípios educativos que preparam os futuros professores contribuindo para compreensão da carreira docente e ampliando a visão do que é ser docente (Pereira, 2016). Acreditamos que a partir do estágio supervisionado o professor aprendiz estará apto para prosseguir sua jornada acadêmica desempenhando a missão de transmitir e construir conhecimentos.

Dessa forma, o estágio ajuda a desvelar algumas atitudes e pensamentos subjetivos que deram forma a nossa escolha pela docência. A busca pela habilitação foi alcançada, porém, a formação continuada deve ser constante para sermos, cada vez mais, agentes mediadores do conhecimento e de novos saberes. A profissão docente é uma arte e deve ser apreciada e valorizada, pois, somos responsáveis pela formação de pessoas e consequentemente da sociedade que vivemos e que desejamos para o futuro.

O estágio fez com que nos confrontássemos com o campo escolar nos fazendo agir em consonância com tantas singularidades presentes nesta atividade. $O$ estágio possibilitou um encontro íntimo com as incertezas, mas sanou muitas dúvidas, desencadeou talentos que duvidávamos ter, despertando desejos profissionais que antes não tínhamos. Acima de tudo, foi fonte de autoconhecimento e junto com este misto de emoções e vitórias, trouxe grande satisfação.

\section{Considerações finais}

O Programa Especial de Graduação objetiva a formar professores para a educação profissional e tecnológica. Na prática, os alunos aprendem observando os professores das licenciaturas. As aulas são divididas em momentos e os futuros docentes são apresentados às metodologias de ensino, ao currículo, às políticas públicas na educação, ao projeto político-pedagógico, às técnicas de ensino inclusivo, à pesquisa, ao planejamento didático-pedagógico, aos planos de aula.

A educação é um tema que permeia toda sociedade, muitos teóricos a conceituam e seu entendimento requer a compreensão da sua historicidade. Para este relato de experiência definimos que a educação é a transferência de conhecimentos, costumes, valores, experiências vividas de uma geração para a geração seguinte. Assim, consideramos que a educação profissional é um processo contínuo de desenvolvimento das faculdades físicas, intelectuais e morais do ser humano, a fim de melhor se integrar na sociedade ou no seu próprio grupo (Freire, 1986).

A formação de professores promoveu o conhecimento de metodologias ativas e inovadoras que permitem ao professor aprendiz ampliar sua visão de sala de aula, organizando pedagogicamente sua prática. Finalizamos com a compreensão de que educar vai além dos limites do ambiente físico, é um ato que poder ser transmitido em qualquer espaço, a qualquer momento.

\section{Referências}

FREIRE, Paulo. A pedagogia da autonomia: saberes necessários à prática educativa. Rio de Janeiro: Paz e Terra, 1996.

FREIRE, Paulo; SHOR, Ira. Medo e ousadia: o cotidiano do professor. Rio de janeiro: Paz e Terra, 1986.

IMBERNÓN, Francisco. La formación y el desarrollo professional del professorado: hacia uma nueva cultura professional. Barcelona: Graó, 1994.

\begin{tabular}{|l|l|l|l|l|l|}
\hline Regae: Rev. Gest. Aval. Educ. & Santa Maria & v. 7 & n. 14 & Jan./abr. 2018 & p. $105-110$
\end{tabular} 
PEREIRA, Marcos Vilella. Estética da professoralidade: um estudo crítico sobre a formação do professor. Santa Maria: UFSM, 2016.

PIMENTA, Selma Garrido; LIMA, Maria Socorro L. Estágio e docência. São Paulo: Cortez, 2004.

SAVIANI, Demerval. Pedagogia histórico-crítica: primeiras aproximações. São Paulo: Cortez, 1992.

Janaína de Arruda Carilo Schmitt é bacharel em Administração de Empresas e estudante no Programa de Pós-Graduação em Educação Profissional e Tecnológica - Ctism/UFSM.

Endereço: Rua Demétrio Ribeiro, 148/301 - 97070-270 - Santa Maria - RS - Brasil.

E-mail: janainacarilo@hotmail.com.

Lubia Telma Garcia Wustrow Souza é bacharel em Administração e integrante do Grupo de Pesquisa: Metodologias Ativas para EPT/UFSM.

Endereço: Rua dos Andradas, 745/407 - 97010-031 - Santa Maria - RS - Brasil.

E-mail: lu.adm2015@hotmail.com.

Recebido em 12 de outubro de 2017.

Aceito em 4 de dezembro de 2017. 